\title{
Acerca de los significados del marcador adverbial dizque en el español de México: una aproximación desde el Enfoque dialógico de la argumentación y la polifonia
}

\author{
Adrián Rodrigo Martínez Levy \\ Investigador en Lengua Española \\ Instituto de Lingüistica \\ Universidad de Buenos Aires \\ 25 de Mayo $217 / 221,1^{\circ}$ piso \\ (C1002ABE) Ciudad Autónoma de Buenos Aires \\ E-mail: adrn.martlev@gmail.com
}

\section{ACERCA DE LOS SIGNIFICADOS DEL MARCADOR ADVERBIAL DIZQUE EN EL ESPAÑOL DE MÉXICO: UNA APRO- XIMACIÓN DESDE EL ENFOQUE DIA- LÓGICO DE LA ARGUMENTACIÓN Y LA POLIFONÍA}

RESUMEN: Este artículo introduce una caracterización polifónico-argumentativa del marcador 'dizque' focalizada en los distintos significados con que se expresa en el español de México. Se utilizará el Enfoque dialógico de la argumentación y la polifonía, una teoría no-referencialista y no-intencionalista del significado lingüístico, que parte de una noción dialógica de la subjetividad para concebir el lenguaje. Esto es, el modo en que se instalan perspectivas responsivas frente a la alteridad discursiva inscrita en el enunciado. Se defenderá que existe una diferencia entre el significado canónico del término, cuyo origen gramaticalizado (dice/n que $\rightarrow$ dizque) es de naturaleza evidencial-citativa, y su expresión irónica. Tal diferencia radica en que, por un lado, el locutor queda deslindado de la responsabilidad del discurso ajeno que comunica, manifestando así una actitud de precaución y/o dubitación. Y, por otro, que dicha responsabilidad es tan solo aparente (fingida), por lo que la enunciación irónica resulta en una descalificación y/o reproche de aquello que presuntamente se reporta.

PALABRAS CLAVES: semántica argumentativa; polifonía; dialogismo; evidencialidad; ironía.

SUMARIO: 1 . Introducción. 2. El Enfoque dialógico de la argumentación y la polifonía. 2.1. La evidencialidad desde el EDAP. 3. La ironía desde el marco del EDAP. 4. Los procesos de grama-/pragmaticalización de dizque y sus distintas modalidades. 4.1. Modalidad evidencial citativa canónica. 4.2. Modalidad irónica. 5. Conclusión.

Fecha de Recepción Fecha de Revisión Fecha de Aceptación Fecha de Publicación
ABOUT THE MEANINGS OF THE ADVERBIAL MARKER SAYS IN THE SPANISH OF MEXICO: AN APPROXIMATION FROM THE DIALOGICAL APPROACH OF ARGU MENTATION AND POLYPHONY

ABSTRACT: This paper seeks to carry out a polyphonic-argumentative characterization of the different meaninfs with which dizque is expressed in Mexican Spanish. We will use the Dialogic Approach of Argumentation and Polyphony, a non-referentialist and non-intentionalist theory of linguistic meaning, which departs from a dialogical notion of subjectivity to conceive language. That is, the way in which responsive perspectives towards discursive alterity are inscribed in statements. Thus, we will seek to defend that there is a difference between the canonical meaning of the term, whose grammaticalized origin (someone says that $\rightarrow$ dizque) is of an evidential-citing nature, and it's ironic expression. Such difference is explain, on the one hand, through the fact that the locutor is detached from the responsibility of the alien discourse that conveys his utterance, thereby manifesting an attitude of caution and/or dubitation. And, on the other, where such responsibility is only apparent (feigned), so the ironical enunciation results in a disqualification and/or reproach of what allegedly is reported.

KEY WORDS: argumentative semantics; polyphony; dialogism; evidentiality; irony.

SUMMARY: 1 . Introduction. 2. The Dialogic Approach of Argumentation and Polyphony. 2.1. Evidentiality from DAAP's Framework. 3. Irony from DAAP's Framework. 4. The Processes of Grama-/Pragmaticalización of Dizque and its various Modalities. 4.1. The Canonical Evidential-Citing Modality. 4.2. The Ironical Modality. 5. Conclusion.

\section{À PROPOS DES SENS DU MARQUEUR ADVERBIAL DIZQUE DANS L'ESPAGNOL DU MEXIQUE: UN RAPPROCHEMENT DE L'APPROCHE DIALOGIQUE DE L'ARGUMENTATION ET DE LA POLYPHONIE}

RÉSUMÉ: Le présent article cherche à réaliser une caractérisation polyphonique et argumentative des différentes modalités avec lesquelles le marqueur "dizque" est exprimé en l'espagnol mexicain. On utilisera L'Approche Dialogique de l'Argumentation et de la Polyphonie, une théorie non-référentialiste et nonintentionnaliste de la signification linguistique, qui fait partie d'une notion dialogique de la subjectivité pour concevoir le langage. C'est-à-dire, la façon dont les perspectives responsives sont installées devant l'altérité discursive dans l'énoncé. Ainsi, on soutiendra le fait qu'il existe une différence entre le sens canonique du terme, dont l'origine grammaticalisée (quelqu'un dit $\rightarrow$ dizque) est de nature évidentielle-évocatrice, et son expression ironique. Une telle différence s'explique, d'une part, par le fait que le locuteur est séparé de la responsabilité $\mathrm{du}$ discours étranger qui traduit son énoncé, manifestant ainsi une attitude de prudence et / ou de dubitation. Et, de l'autre, que telle responsabilité est seulement feinte, de sorte que l'énonciation ironique entraîne une disqualification et / ou un reproche de ce qui est rapporté.

MOTS CLÉS: sémantique pholyphonie; dialogisme; évidentialité; ironie.

SOMMAIRE: $1 . \quad$ Introduction. 2. L'Approche dialogique de l'argumentation et de la polyphonie. 2.1. L'évidentialité de l'ADAP. 3. L'ironie du cadre de l'ADAP. 4. Les processus de grama-/pragmaticalisation de dizque et ses diverses modalités. 4.1. La modalité canonique évidentielle et de citation. 4.2. La modalité ironique. 5 . Conclusion. 


\title{
Acerca de los significados del marcador adverbial dizque en el español de México: una aproximación desde el Enfoque dialógico de la argumentación y la polifonia
}

\author{
ADRIÁN RODRIGO MARTÍNEZ LEVY
}

\section{INTRODUCCIÓN}

El marcador adverbial ${ }^{1}$ dizque ha inspirado numerosos y variados estudios lingüísticos. Una línea prominente entre estos estudios es aquella que indaga acerca de los procesos de gramaticalización que llevaron del sintagma verbal referencial dice $(n)^{2}$ que al marcador univerbado de función adverbial dizque (Kany, 1944; Magaña, 2005; Alcázar, 2014; Grajales, 2017, entre otros). Otro conjunto importante de trabajos se ha dedicado a explicar lo que en estos se define como valor pragmático evidencial y modalidad epistémica de este vocablo (Travis, 2006; Dumitrescu, 2011; De la Mora y Maldonado, 2015; Philer, 2018, entre otros). No obstante, pocos han sido los casos en que hemos encontrado estudios que expliquen la dimensión irónica presente en el empleo de dizque. Si bien es cierto que Olbertz $(2005,2007)$ realiza un par de menciones acerca de este fenómeno, identificando en el español de Ecuador y México ${ }^{3}$, su tratamiento es carente de profundización y, sobre todo, de ejemplos.

A lo largo de este trabajo, buscaremos mostrar que en el marcador adverbial dizque, en México, coexisten gradualmente diversos significados y efectos de sentido concomitantes: citativo $\rightarrow$ neutralidad; evidencial $\rightarrow$ precaución epistemológica; irónico-sarcástico $\rightarrow$ descalificación del otro y autoirónico $\rightarrow$ burla hacia uno mismo. ${ }^{4}$ Utilizaremos el Enfoque dialógico de la argumentación y la polifonía (de aquí en más EDAP, García Negroni, Libenson y Montero, 2013; García Negroni, 2009, 2016, 2017, 2019; García Negroni y Libenson, 2015, 2016, Martínez Levy, 2017) ${ }^{5}$ dado que, por un lado, nos permite identificar y explicar la compleja arquitectura polisémica de este marcador. Y, por otro, nos brinda las herramientas teórico-conceptuales

\footnotetext{
${ }^{1}$ De manera general, partimos de la idea de dizque como un marcador discursivo (Zorraquino y Portolés, 1999), es decir, como unidad lingüística especializada en encadenar diferentes fragmentos discursivos, señalando explícitamente el tipo de relación semántica que existe entre ellos y guiando así la interpretación del discurso que se transmite.

${ }^{2}$ Se conoce la forma apocopada dize del español antiguo que refería al pretérito de segunda y tercera persona (dijo, dijeron).

${ }^{3}$ El Diccionario del español de México (DEM) se señala: 'dizque': adv (Coloq) Supuestamente, según parece, según dice o según se dice, expresado con ironía o duda.

${ }^{4}$ Como dijimos, existe una caracterización similar en el español Ecuatoriano (Olbertz, 2005): "En su descripción del uso de dizque, Toscano Mateus (1953: 296-298) concluye que en el Ecuador dizque ha sufrido un cambio semántico gradual de su sentido original en tres fases: "dizque (= dicen que > dijo que, dices que, etc.) > algo que dice otro o que dicen otros, y, por tanto, algo de cuya realidad no se responde $>$ falsedad, irrealidad, suposición, ironía" (Toscano Mateus 1953 en Olbertz, 2005: 78). No obstante, el señalamiento de este fenómeno resulta tan estéril como la simple mención en la cita.

${ }_{5}^{5}$ Agradezco a María Marta García Negroni por su atenta lectura de mi trabajo.
} 
para establecer una novedosa caracterización de sus formas de expresión evidencial e irónica. Si bien es cierto que el EDAP se ha encargado recientemente en caracterizar teóricamente el fenómeno de la evidencialidad, todavía hace falta indagar sobre los mecanismos que la ironia echa a andar en la enunciación.

La organización del presente artículo es la siguiente. Primero, introduciremos el marco teórico del EDAP. Después, brindaremos un breve estado del arte de los estudios sobre evidencialidad, en donde contrastaremos las aproximaciones semántico-pragmáticas antes mencionadas y las recientes aportaciones que ha brindado el EDAP (García Negroni, 2017, 2019; García Negroni y Libenson, 2015, 2016) (§ 2.1). Asimismo, daremos una breve explicación contrastiva de los estudios sobre ironia, marcando nuevamente un contraste entre el EDAP y otras formulaciones (§ 2.2). Una vez establecidas las bases sobre las cuales se edifica este trabajo, explicaremos detalladamente los procesos de grama/-pragmaticalización de dizque (§ 3). E introduciremos los distintos significados que vehiculiza este marcador, a la par de una serie de ejemplificaciones extraídas de diversas fuentes, que resultan pertinentes a nuestra exposición (§ 4.1, 4.2 y 4.3). Para finalizar, concluiremos y redondearemos los elementos más relevantes de nuestra propuesta y el análisis llevado a cabo (§ 5).

\section{EL EDAP}

El EDAP retoma algunas aportaciones teóricas del Dialogismo (Bajtín, 1979), la Polifonía enunciativa (Ducrot, 1984) y la Semántica argumentativa (Anscombre y Ducrot, 1983; Anscombre, 1995, Ducrot, 2004 y Carel y Ducrtot, 2005) con el propósito de construir una teoría centrada en el funcionamiento de la lengua y el discurso (García Negroni, 2019: 2).

El enfoque retoma de la polifonia la idea de que en el enunciado coexisten múltiples voces (o puntos de vista) que no necesariamente son atribuidos a su autor (Ducrot, 1986). De modo que el "sujeto hablante", único e intencional, que delinea la pragmática anglosajona resulta ser, para este enfoque, exterior al sentido. Y, por consiguiente, es ineludible identificar a los responsables virtuales de la enunciación.

Originalmente, la teoría polifónica planteaba una primera dicotomía entre locutor y enunciador para establecer los diferentes origenes enunciativos de los contenidos vehiculizados por el enunciado. El locutor es conceptualizado como el "responsable de la enunciación" (ibid.), mientras que el enunciador se remite al origen de las diferentes posiciones adoptadas en los contenidos vehiculizados (ibíd.). ${ }^{6}$ En efecto, el significado citativo de dizque se remite a esta disociación de orígenes enunciativos, en donde el locutor $\mathrm{L}$

\footnotetext{
${ }^{6}$ Conviene aclarar que la noción de enunciador termina siendo abandonada tanto por Ducrot como por el EDAP. Esto se debe a que su conceptualización conllevaba algunas reminiscencias referencialistas, en tanto que remite a personas reales como el origen de los contenidos vehiculizados en el enunciado. Ducrot (2010) prefiere utilizar la noción de modos de atribución (fr. modes du donation), mientras que el EDAP opta por la noción de puntos de vista.
} 
retransmite un discurso ajeno. Por lo mismo, este significado conlleva un efecto de sentido neutral.

Además, el autor francés introduce una dicotomía al interior de la noción de locutor, entre L y $\lambda$, cuya diferencia es que el último se remite a un "ser del mundo". $\Lambda$ es la imagen enunciativa a quien remiten las marcas de primera persona, es decir, de quien se habla en el enunciado que las contiene. Esta diferencia puede apreciarse claramente en los performativos explícitos, por ejemplo, yo deseo:

"[...] no es en tanto locutor que se experimenta el deseo, sino en tanto 'ser del mundo', independientemente de la aserción que se hace de él. En cambio, el acto de deseo, que no existe más que en el habla en la que se realiza, pertenece típicamente a $\mathrm{L}$ : $\mathrm{L}$ realiza el acto de deseo acertando que $\lambda$ desea [...] L es considerado responsable de la enunciación, considerando únicamente en virtud de esta propiedad. $\Lambda$ es una persona 'completa', que entre otras propiedades posee la de ser origen del enunciado; lo que no impide que L y $\lambda$ sean seres de discurso, construidos en el sentido del enunciado, y cuyo estatuto metodológico es por tanto completamente distinto del sujeto hablante (este corresponde a una representación 'externa' del habla, extraña a la que el enunciado vehiculiza). (Ducrot, 1986: 204)" (Ducrot, 1986: 202204). ${ }^{7}$

En lo referente a la argumentación, el EDAP retoma las tesis fundadas en la Teoría de la argumentación en la lengua (TAL, por sus siglas en francés), la cual dicta que el valor semántico depende de ciertas funciones argumentativas ancladas al sistema lingüístico (Anscombre y Ducrot, 1983). De este modo, sumándose al rechazo de la unicidad del sujeto hablante, para el EDAP resulta esencial desinformativizar la semántica. Ducrot (2004) y Carel y Ducrot (2005) introdujeron la Teoría de los bloques semánticos (de aquí en más, TBS) para ampliar la base teórica de la TADL. En primera instancia, sumaron a los encadenamientos de tipo conclusivo (en por lo tanto, PLT) aquellos de tipo concesivo (en sin embargo, $S E$ ), definiendo a los primeros como normativos y a los segundos como transgresivos (Carel y Ducrot, 2005: 13). También introdujeron las nociones de encadenamiento argumentativo e interdependencia semántica para dar cuenta de la vinculación inherente entre los segmentos que configuran el sentido (ibid.: 16-24). Asimismo, delinearon la idea de bloque semántico para señalar la relación que guardan entre sí los significados que surgen al definir argumentativamente cualquier expresión (palabra, sintagma, enunciado o discurso) (ibíd.: 25-49). Es decir, que al definir una expresión, no solo se la define a ésta, sino que también se activan ciertos significados que orbitan a su alrededor.

\footnotetext{
${ }^{7}$ Cabe mencionar que el EDAP se distancia de la reconocida metáfora teatral de que el locutor es una especie de "titiritero que pone en escena" a distintos personajes que juegan papeles dentro de la enunciación.
} 
Otro conjunto de definiciones que retoma el EDAP de la TBS es la diferenciación entre argumentaciones externas (AE) e internas (AI) en la descripción semántica de las expresiones (ibíd.: 62-67). En las AE, las palabras o términos de una expresión participan en los encadenamientos que las describen. De modo que su significación puede tener o bien un origen estructural (dado por el sistema lingüístico) o bien un origen contextual (dado por el co-texto sintagmático). Mientras que en las AI ninguno de los términos que forma parte de la expresión participan en los encadenamientos que la describen, por lo que su significación solo puede darse estructuralmente.

En cuanto al dialogismo, el EDAP retoma la idea de que ninguna palabra es neutra, sino que se encuentra cargada, habitada o atravesada por los discursos en los que vivió su existencia socialmente determinada (Bajtín, 1979). Asimismo, este enfoque se alinea con la teoría de las Heterogeneidades enunciativas (Authier-Revuz, 1984) cuya premisa es que los discursos anteriores constituyen una condición inherente de cada expresión.

En síntesis, el EDAP parte de una descripción polifónico-argumentativa de la significación lingüística vista desde una perspectiva dialógica de la enunciación. De modo que, como parte constitutiva de la caracterización del sentido, es preciso identificar los posicionamientos responsivos que configuran la dimensión dialógica de la (inter-)subjetividad. ${ }^{8}$ Punto por punto, este enfoque plantea: (a) no existe elemento de la significación cuyo carácter sea puramente objetivo, (b) el sentido de toda entidad lingüistica está constituido por el conjunto de encadenamientos argumentativos que esa entidad evoca, (c) los diversos puntos de vista que se expresan en la enunciación no necesariamente reflejan la intención de una única y misma figura discursiva y (d) el discurso y el sujeto están constitutivamente atravesados por la presencia del otro (García Negroni, 2019).

\subsection{LA EVIDENCIALIDAD}

Como dijimos, en años recientes, el estudio de la evidencialidad lingüística ha encontrado un particular desarrollo con el EDAP, el cual se opone radicalmente al abordaje de este fenómeno enmarcado en teorías pragmáticas de corte cognitivista, referencialista e intencionalista (Chafe \& Nicols, 1986; Blakemore, 1994; Aikhenvald, 2004, 2006; Cornillie, 2007). Desde estas perspectivas, la evidencialidad se concibe como un mecanismo que indica el modo cognitivo (directo o indirecto) con que se accede a la información que quiere comunicar el hablante (Aikhenvald, 2004). La fuente es directa cuando se trata de un conocimiento adquirido perceptualmente por alguno de los sentidos (vista, oído y olfato). Si la fuente es indirecta, se trata de conocimientos que proceden ya sea de una inferencia razonada, o bien, de un discurso ajeno (Anderson 1986; Willet 1988).

\footnotetext{
8 Cabe aclarar, que la noción de (inter-)subjetividad es entendida por el EDAP como el modo en que se instalan perspectivas de respuesta y anticipación discursiva frente a la alteridad discursiva inscrita en el enunciado (García Negroni, 2009).
} 
Por su parte, el EDAP (García Negroni y Libenson, 2015 y 2016; García Negroni, 2019) plantea que, más allá de las condiciones del mundo, los conocimientos y las intenciones; la evidencialidad tiene más que ver con la evocación o modificación de los discursos argumentativos presentes en el sentido de ciertas entidades lingüísticas (como lo es dizque). Asimismo, este enfoque señala que para recuperar cabalmente el significado evidencial es preciso identificar el posicionamiento (inter-)subjetivo con que el locutor queda atado a su enunciación (ibíd.).

Recordemos que, según Ducrot (1986: 74), existen cuatro clases de instrucciones semánticas que permiten dar cuenta del sentido: las polifónicas, las ilocucionarias, las argumentativas y las causales. Conforme a ello, García Negroni y Libenson (2016) afirman que la evidencialidad se caracteriza por incluir como parte de sus instrucciones la calificación del habla como la causa de su enunciación. De tal manera, es preciso mostrar que dicha representación causal se encuentra prefigurada bajo la forma de marcos de discurso (García Negroni, 2009, 2019) ${ }^{9}$ en los que cierta representación discursiva de percepciones y decires quedan articuladas normativa o transgresivamente con aserciones sobre $\lambda$ respecto de ellas (García Negroni, 2019).

Así pues, uno de los significados asociados a dizque es vehiculizado por un punto de vista evidencial indirecto que obliga a recuperar las causas de la enunciación a partir de un marco de discurso en donde quedan establecidas distintas relaciones ente $\lambda$ y los discursos citados o evocados. Esto lo veremos más claramente al dar cuenta de los procesos de grama/-pragmaticalización a través de los cuales este vocablo pasó de ser citativo (instrucción polifónica) a ser un marcador de distanciamiento precautivo del locutor sobre un reportado (instrucción causal). Como intentaremos mostrar, la raíz del verbo decir opera de distinta manera en cada caso. Mientras que en la retrasmisión neutral de discurso ajeno $(\mathrm{L} \neq \mathrm{L} 2)$ solamente queda plasmado que el contenido vehiculizado por el enunciado remite a un locutor distinto de L; en la retransmisión evidencial, aparte de que L queda distanciado del contenido vehiculizado, es posible identificar la calificación del habla distanciada como causa de la enunciación en la que dizque aparece.

\subsection{LA IRONÍA}

Nuevamente, hemos decidido partir de la teoría polifónica de la ironía (Ducrot, 1986, 2010) con el fin de establecer, bajo los términos del EDAP, un tercer significado de dizque. La particularidad de este significado radica en los posicionamientos subjetivos de descalificación a terceros o autoburla, cuya identificación es vital para comprender el sentido de esta clase

\footnotetext{
${ }_{9}$ García Negroni introdujo la noción de marco de discurso como caracterización argumentativa de la situación de habla (García Negroni 2009: 79). Más tarde, la misma autora amplía esta noción y explica que los marcos de discurso consituyen un encadenamiento argumentativo en la que se funda la enunciación en la que se expresan y frente al cual queda constituido el posicionamiento subjetivo de respuesta que se manifiesta en el enunciado (García Negroni, 2019: 2).
} 
de enunciaciones. Conviene aclarar que el concepto de ironía ha sufrido, también, una serie de cambios conceptuales a lo largo del desarrollo de esta tradición de pensamiento. Originalmente, la conceptualización de Ducrot (1986) acerca de este fenómeno era la siguiente:

[En la ironia] La posición absurda es directamente expresada (y no transmitida) en la enunciación irónica, y al mismo tiempo no es puesta a cargo de L [...]. En la ironía es esencial que el locutor no ponga en escena a otro enunciador [E'], quien por su parte sostendría el punto de vista razonable. Si el locutor debe marcar que él es distinto de E', lo hace de forma muy diferente, recurriendo por ejemplo a una evidencia situacional, a entonaciones particulares y también ciertos giros irónicos (Ducrot, 1986: 215-2016).

Ducrot (2010) termina por abandonar el concepto de enunciador y lo sustituye por modos de atribución ( $\S$ nota 7 ), según los cuales los contenidos existen en los enunciados. ${ }^{10}$ Así, el autor define que las enunciaciones irónicas vehiculizan contenidos concebidos, cuya particularidad es que se configuran en la enunciación misma y no forman parte de una opinión previa del locutor.

Dans mon ancienne théorie de la polyphonie (celle qui voyait les énonciateurs comme des individus), on aurait pu exprimer cela en disant que le locuteur ironique assimile toujours à lui-même l'énonciateur du contenu intenable. Mais cette description de l'ironie peut sembler contraire aux faits, elle peut sembler contraire notamment au fait que l'on ironise souvent contre les opinions des autres [...]. Avec la nouvelle théorie de la polyphonie, on ne court plus ce risque, car on peut distinguer nettement le problème rhétorique de l'origine de l'opinion intenable, qui est un problème de critique textuelle, et le problème linguistique, sémantique, de ce que dit le locuteur au moment de l'énonciation (Ducrot, 2010: sp).

Cabe añadir que en el trabajo recién citado, de título Ironie et négation, Ducrot busca comparar la ironía con el fenómeno de la negación morfológica, es decir, aquella que está lingüísticamente marcada con el adverbio no (fr. ne... pas). Como parte de sus conclusiones, el autor advierte que en la negación se configura el ethos razonable de un locutor que se opone abiertamente a lo que niega. Mientras tanto, en la ironía se construye el ethos irracional (ingenuo) de un locutor que sostiene lo insostenible. ${ }^{11}$ La diferencia entre ironia (simple y satírica) y autoironía radica en que el discurso insostenible/absurdo se remite o bien a un interlocutor o a un tercero (mientras más identificable, más satírico) o bien a una imagen que el locutor crea sobre sí mismo $(\lambda)$.

\footnotetext{
10 Propuestos originalmente por Carel (2006), existen cuatro modos de atribución (fr. modes de donation): hallados (fr. trouvés), recibidos (fr. reçus), concebidos (fr. conçus) y modos de testigo. ${ }^{11}$ Para este viraje conceptual es clave la concepción del locutor como un "falso ingenuo" (Berredonner, 2002) que sostiene discursos abiertamente absurdos.
} 
Resta añadir al significado citativo (instrucción polifónica en que L retrasmite discurso de L2 neutralmente) y al significado evidencial (instrucción dialógico-causal de precaución epistemológica: L se distancia del discurso de L2), el significado irónico de dizque, cuya enunciación obliga a recuperar un marco de discurso argumentativo que muestra al discurso reportado de L2 como absurdo (instrucción polifónico-causal de descalificación a terceros/burla de sí mismo: L presenta el discurso de L $2 / \lambda$ como absurdo).

En efecto, el empleo irónico de dizque hace ver al locutor como sí estuviera deslindado de aquello que retransmite (significado evidencial), pero, en el fondo, muestra un alto compromiso de crítica o auto-burla. Como veremos a continuación, esto es posible gracias los procesos de grama-/pragmaticalización que forman parte del significado del propio vocablo. Se trata, por un lado, de una pérdida del carácter citativo producida al pasar de los sintagmas dice(n) que/se dice que a la univerbación dizque con mayor distanciamiento enunciativo. Y por otro lado, al menos en los casos del español de México (y el caso de Ecuador citado en la introducción), es posible hablar de un retorno hacia el compromiso enunciativo que muestra a la enunciación como una descalificación implícita o burla desenfadada de aquello que presuntamente reporta.

\section{LOS PROCESOS DE GRAMA-/PRAGMATICALIZACIÓN DE DIZQUE Y SUS DISTINTOS SIGNIFICADOS}

Como se ha señalado, este artículo aborda los distintos significados con que se expresa el marcador adverbial dizque, cuyo origen, sujeto a un proceso gramaticalización, proviene de los sintagmas regidos por los sintagmas de alta productividad en el español dice(n) que y se dice que:

\footnotetext{
"Durante algunos siglos -de manera más relevante en XV y XVI, según datos del CORDE- convivieron las formas dize que y diz que para expresar la forma presente del verbo decir e introducir una completiva de sustantivo. Aunque tienen un uso muy similar, en la mayoría de los ejemplos se prefiere la forma "larga" para codificar sujetos marcados y conocidos; mientras que la forma apocopada se muestra en construcciones [...] con un significado verbal pleno y pérdida de sujeto" (Magaña, 2005: 65).
}

Con el tiempo, la univerbación dizque trajo consigo el debilitamiento de su forma verbal, pérdida de transitividad y de deixis temporal así como el reforzamiento del significado pragmático de duda, que surge en contextos de creencias (Magaña, 2005). La autora señala (inscrita en un marco intencionalista) que el proceso de gramaticalización de esta expresión es: a) Dice $q u e=$ forma verbal $($ decir $>$ dice $)+$ nexo $(q u e)$. Significado verbal pleno que introduce completiva (hay una marca de sujeto o de impersonal). $>$ b) Diz $q u e=$ forma verbal $($ decir $>$ diz $)+$ nexo $(q u e)$. Significado verbal pleno, el nexo introduce una completiva, hay impersonales y en la mayoria de los casos el sujeto es una entidad colectiva y conocida que se repite a lo largo del discurso. $>$ c) Diz que $=$ forma verbal (decir $>$ dice) + nexo (que). Significado 
verbal pleno, pérdida del sujeto. $>$ d) Dizque= univerbación de las formas dice y que, debilitamiento de la forma verbal, pérdida de transitividad y deixis temporal. Recarga de significado pragmático: "no me consta", surge en contextos de creencias. > e) Pierde la posibilidad de ser calificado previamente por marcas de negación. $>$ f) Dizque = rigidización de la forma, puede aceptar otro nexo que (Magaña, 2005: 64-66).

Ahora bien, no obstante este vocablo puede hallarse constantemente en distintas zonas de América Latina, como en Medellin, Colombia (Grajales, 2017) y Ecuador (Olbertz, 2005; García Fajardo, 2009), en el español de México presenta un prominente uso irónico (Olbertz, 2007). Este empleo simula vehiculizar el significado evidencial, ya que, lejos de significar duda ("es posible"/"no me consta"), tiene la función de exhibir una contradicción o inconsistencia o bien de lo dicho por alguien más (L2) o bien de lo dicho por uno mismo $(\lambda)$ o bien de un rumor (L-rumor) o bien del sentido común (L-doxa) 12.

Es preciso insistir que para poder interpretar el sentido las enunciaciones en que aparece dizque es preciso recuperar los marcos de discurso argumentativos (MD, señalados ente corchetes) que fungen como la causa de su enunciación, así como los posicionamientos subjetivos que L hace sobre el discurso ajeno (L2) o sobre su propio discurso (García Negroni, 2019 y comunicación personal).

No está de más insistir que nuestro objetivo es mostrar que existe un continuum semántico entre el dizque (1) citativo (neutro) $<>$ (2) evidencial (precautivo) <> (3) irónico (descalificativo) <> (4) auto-irónico (bromista).

\subsection{SigNificAdo CITATIVO}

El significado citativo de dizque vehiculiza un contenido [X] que remite a un discurso ajeno (L2). Dado que se trata de casos de discurso referido (es posible que este discurso aparezca reproducido de forma directa, a través de segmentos entrecomillados, o de forma indirecta. Otra regularidad es que esta clase de dizque tiene que remitir siempre a una tercera persona del singular (él/ ella).

L2: -Pregúntale que si conoció a Guadalupe Terreros.

\footnotetext{
12 El concepto de doxa es ampliamente utilizado por Ducrot y sus colegas (Ascombre y Ducrot, 1983; Ducrot, 1984 y Anscombre, 1995) para señalar ideas comúnmente aceptadas que sirven como garantes argumentativos de ciertos significados. En un principio denominaron estas instancias "topoi", aludiendo a la noción aristotélica de "lugar común" (Anscombre y Ducrot, 1983). Por ejemplo, el topos soleado por lo tanto lindo día es mucho más común que nublado por lo tanto lindo día, lo cual, no significa, empero, que "un lindo dia" tenga que ser forzosamente soleado, sino que esa idea es mucho más generalizada. Más adelante, Ducrot y Carel $(1999,2005)$ reformularon el concepto de los topoi, ya que su naturaleza escalar (i.e., mientras más soleado, más lindo el día) resulta un tanto referencialista. Y prefieren llamar encadenamientos doxales a la vinculación de aspectos comúnmente asociados. Así, los encadenamientos lingüísticamente doxales (Carel y Ducrot, 1999) son aquellos encadenamientos que se fundan en la argumentación interna o externa-estructural de alguno de sus términos.
} 
L1: -Que dizque si conociste a Guadalupe Terreros.

(El llano en llamas, Juan Rulfo, versión digital: s. p.)

El ejemplo (1) se trata de una clara y rotunda retransmisión de discurso ajeno en modalidad indirecta, que surge de una petición de información por parte de L2 (a un tercer personaje desconocido), la cual es retransmitida por L1. Este es, sin duda, un empleo canónico de citación sin ninguna otra facultad semántica. Es más, como señala Magaña (2005), al recién rigidizarse la forma, esta modalidad puede presentarse en oraciones encabezadas por otro nexo que con antecedente explícito. En este caso, el antecedente funge una paráfrasis directa de que dice que, cuyo foco (o tema) es el decir de L2, no precisamente el contenido $\mathrm{X}$ vehiculizado por ese discurso.

\section{$\{\mathrm{L} 1:$ dice $X$ (= [L2 pregunta que: $]$ si conociste a Guadalupe Terreros) $\}$}

Cosa distinta ocurre cuando el foco no resulta ser tan nítido, como es el siguiente caso:

(1) Dice que le dijo que ya se había curado por fin; que ya no le molestaba ningún dolor. "Ya puedo estar contigo, Natalia. Ayúdame a estar contigo", dizque eso le dijo.

(El llano en llamas, Juan Rulfo, versión digital: s. p.)

En (2) es posible identificar un complejo entramado de discursos referidos introducidos por el locutor principal (L1), que transmite el decir de L3 a través de L2. Las dos primeras oraciones se introducen en modalidad indirecta, mediante dos estructuras subordinantes superpuestas: dice (L2-Natalia) que le dijo (L3-desconocido) que X (= ya se habia curado) y que Y (= ya no le molestaba ningún dolor). La tercera oración se presenta en modalidad de discurso directo mediante un segmento entrecomillado atribuido a L3 que vehiculiza el contenido Z (= Ya puedo estar contigo, Natalia. Ayúdame a estar contigo). Finalmente, el enunciado introduce una cuarta oración anafórica encabezada por dizque, que reafirma el origen ajeno de los discursos vehiculizados a lo largo de la enunciación.

\{L1 dice que $X(\mathrm{DI}=$ ya se había curado), $Y(\mathrm{DI}=$ ya no le molestaba ningún dolor), $Z$ (DD= "Ya puedo estar contigo, Natalia. Ayúdame a estar contigo")\}

Como dijimos, desde nuestra perspectiva, existe una leve diferencia entre (1) y (2), que radica precisamente en la nitidez del foco (o tema) de la enunciación. Mientras que en (1) el foco se concentra claramente en el decir de L2, en (2) el foco comienza a difuminarse entre el decir de L2/L3 y los contenido vehiculizados (X, Y, Z). Esto se debe, según nuestro análisis, al hecho de que (1) remite a una petición explícita de información por parte de L1, que es simplemente retrasmitida por L1. Mientras que en (2) se trata de diversas formas de manifestar que lo dicho (el contenido) no pertenece a L1. A continuación, veremos algunos casos en donde el distanciamiento es mucho más patente y la dimensión dialógica comienza a aparecer. 


\subsection{SigNIFICADO EVIDENCIAL}

Como hemos venido insistiendo, el significado evidencia de las enunciaciones con dizque también reproducen el decir otro, salvo que lo hacen de manera distanciada e incluso escéptica. Por ejemplo:

(2) ¿Qué pasó luego? Yo no lo supe. No volví a trabajar con él. Ni yo ni nadie, porque ese mismo día se murió. ¿No lo sabía usted? Me lo vinieron a decir a mi casa, mientras estaba acostado en el catre, con la vieja alli a mi lado poniéndome fomentos y cataplasmas. Me llegaron con ese aviso. Y que dizque yo lo había matado, dijeron los díceres. Bien pudo ser, pero yo no me acuerdo.

(El llano en llamas, Juan Rulfo, versión digital: s. p.)

(3) -Que le dé gracias a Dios de que haya un zonzo que jale con el engendro ese.

-Figúrate, dicen que las monjas del Canadá no la quisieron aceptar de pura fea, que dizque desmoralizaba a las demás niñas.

(La región más transparente, Carlos Fuentes, versión digital: s. p.)

(4) ¿Va a haber tiempo para el arrepentimiento? Ni que me regalaran la vida de nuevo para arrepentirse de cada cosa; pero, jay venganza que te tomas, muerte calaca, por andar uno creyendo que eres distinta de la vida! Tú eres todo, la vida te invade, te hiere. La vida no es más que una excepción de la muerte. Ahí vamos dando tumbos, que dizque vamos a ser héroes, para acabar pensando ¿qué se siente cuando una bala de plomo, y luego otra, y otra más, se te clavan en la barriga y en el pecho, qué carajos se siente?

(La región más transparente, Carlos Fuentes, versión digital: s. p.)

En efecto, (3), (4) y (5) son casos de discurso referido, no obstante, a diferencia de (1) y (2), el marco de discurso está mostrado a través de la tercera plural (ellos), el rumor ${ }^{13}$ y la doxa. Asimismo, en estas enunciaciones podemos encontrar distintos efectos de sentido adyacentes a la mera retransmisión neutral del decir otro.

En (3) L1 introduce el discurso de una tercera persona plural que vehiculiza el contenido X (= yo lo había matado), no obstante, diversos elementos del cotexto permiten identificar que no se trata de una reproducción neutral. Tanto el marcador dizque como el pretérito plus cuan perfecto (habia), la sustantivación del rumor (los diceres) y el enunciado concesivo final (bien pudo ser, pero no me acuerdo) sugieren que el locutor a cargo de la enunciación establece un distanciamiento precautivo sobre el decir que comunica. Esto se puede apreciar claramente si recuperamos el MD de discurso evocado y la respuesta dialógica (siempre normativa introducida por un $৬$ POR LO TANTO dialógico) que conlleva una aserción epistémica de duda (precaución epistemológica) del L sobre su enunciación.

\section{$\{$ Dice(n) que X PLT es posible X para $\lambda\}$}

\footnotetext{
13 Para una mayor profundización sobre el estudio del rumor desde el EDAP, consultar la tesis doctoral de Manuel Libenson (2016): El rumor en la práctica bursátil (UBA).
} 
५POR LO TANTO la enunciación de L es precavida.

En efecto, el conector normativo (en PLT) del MD se debe a que la incerteza llega a ser tal como en (3), que no hay razones para introducir una nueva continuación transgresiva que sugiera una rectificación de $\mathrm{X}$.

$\{$ Dicen $X$ (= yo lo habia matado) PLT es posible $X$ (PLT "bien pudo ser $\left.X^{\prime \prime} /{ }^{*} \operatorname{SE~no~} X\right)$.

५POR LO TANTO la enunciación es precavida frente al decir de L ajeno

En (4), al no se remitirse a una persona gramatical, la enunciación apela a un colectivo anónimo representado por un decir rumoroso (L-rumor). De modo que el contenido X (= desmoralizaba a las demás niñas) introducido por dizque también conlleva un distanciamiento epistémico de incerteza, que bien puede asociarse al MD y a la respuesta dialógica antes marcadas. De nueva cuenta, no es posible introducir una continuación que rectifique la orientación normativa del MD antes señalado:

$\{$ Dicen $X$ (= desmoralizaba a las demás niñas) PLT $\lambda$ cree queX (*SE no $X)\}$

५POR LO TANTO la enunciación es precavida frente lo dicho (contenido $\mathrm{X)}$ por L-rumor

En cambio, si bien es cierto que en (5) podemos apreciar un distanciamiento epistemológico del locutor, ahora, frente a la voz de la doxa (L-doxa). También es cierto que la continuación discursiva que admite es ligeramente distinta de las anteriores. Y es que en dizque vamos a ser héroes, el futuro perifrástico (vamos a ser) activa la argumentación externa-estructural del término asociado a 'heroísmo' (heroismo PLT valentía). No obstante, si atendemos a todo el resto del discurso arrepentido del personaje que encarcelado que teme frente su cruel destino, es posible también identificar una argumentación externa-contextual del tipo heroísmo SE temor. Es preciso advertir que ambas argumentaciones guardan entre sí una interdependencia semántica de conversión, la cual es posible identificar al invertir el conector y poner en relación el segundo segmento de ambos encadenamientos (temor $\rightarrow$ neg. valentia):

$\{$ Dicen X (= vamos a ser héroes (heroísmo PLT valentia)) SE no es así para $\lambda$, sino Y (heroísmo SE temor $\rightarrow$ neg. valentia) $\}$

५POR LO TANTO la enunciación de L es escéptica de frente al decir de la doxa.

Este comportamiento rectificativo del sentido asociado al contenido $\mathrm{X}$ constituye un paso más del continuum hacia el significado irónico en dizque. Pero, a diferencia de la ironía, dicha rectificación de significados no supone un decir absurdo o insostenible, sino, más bien, una forma distinta (Y) de 
decir lo mismo que X. En este caso, se trata de un presunto héroe que reconoce su propio temor frente a la desdicha de ser condenado. Podriamos decir que el significado doxal de X ('héroe valiente') es intercambiado por el de Y ('héroe pusilánime'). Es por ello que, además, el posicionamiento subjetivo de respuesta deja de ser del propiamente precautivo y se vuelve, más bien, escéptico frente al significado doxal de X.

Como es posible apreciar hasta aqui, lo que diferencia al significado citativo en (1-2) del significado evidencial en (3-5) es que, si bien ambos se soportan en un decir ajeno (efectivo o potencial), no se manifiestan las mismas causas de la enunciación ni un posicionamiento intersubjetivo único. Es más, incluso al interior del significado evidencial puede haber algunas diferencias.

Significado citativo

(1)

(2)

(3)

(4)

Significado evidencial (cont. X L2) (decir L-3a) (cont. X L-rumor) (decir L-doxa)

Foco: (decir L2)

[+ neutral]

[+ rectificación]

Figura 1:Gradación del significado citativo y evidencial

\subsection{SIGNIFICADO IRÓNICO}

A continuación, buscaremos mostrar que existen ciertos rasgos constitutivos que configuran el sentido irónico de dizque, por lo que estableceremos primero estas regularidades para después ilustrarlas con algunos ejemplos. El locutor irónico (L?) se manifiesta en esta clase de enunciaciones como si se homologara con un discurso insostenible o absurdo, que, en el fondo, remite a un decir ajeno (o bien de un interlocutor o bien de un decir rumoroso o bien del sentido común/doxa). De modo que las enunciaciones irónicas con dizque obligan a recuperar un MD transgresivo que, al tiempo de vehiculizar el contenido X, lo califica como absurdo. Asimismo, es preciso identificar un posicionamiento subjetivo de descalificación (en distintos grados) sobre ese discurso, que se añade dialógicamente a la enunciación:

\{Dice(n) que X SE X es absurdo para $\lambda$ \}

५POR LO TANTO la enunciación de L descalifica el discurso ajeno

(5) Dizque se le aparecieron los marcianos

(Diccionario del Español de México, ejemplo de entrada 'dizque')

En apariencia, (6) presenta a L? como si estuviera homologado con el contenido X (= se le aparecieron los marcianos), el cual remite a un discurso ajeno a través del predicado pronominal (dice que se le aparecieron los marcianos). Pero, si recuperamos el sentido irónico, resulta que, en efecto, la 
enunciación descalifica implícitamente al presunto interlocutor (L2-desconocido) que se le acusa de sostener algo evidentemente absurdo. Ciertamente, lo absurdo surge de la imposibilidad de sostener seriamente que "un marciano se aparezca", ya que aún no existen pruebas de vida en Marte. Hay que aclarar que lo anterior no debe confundirse con un "conocimiento del mundo" (dado que ello resulta irrelevante para nuestro análisis antireferencialista), sino, más bien, como hecho discursivo asociado a un saber común: se sabe que no hay vida en marte (PLT X es absurdo). ${ }^{14}$

$\{$ Dice $X$ (= se le aparecieron los marcianos) $S E X$ es absurdo paras $\lambda\}$

५POR LO TANTO la enunciación descalifica del decir atribuido a L2.

(6) La reforma dizque heducativa (sic)

(Título de libro homónimo, México, 2015)15

Nuevamente, podemos apreciar que L? aparece como si sostuviera el contenido X (= [cualidad] heducativa), que, a su vez, califica al núcleo nominal del sustantivo complejo reforma heducativa, del cual dizque es modificador adverbial. No obstante, más allá de la marca ortográfica de distanciamiento autonímico (manifiesta en la errata: heducativa), es preciso recuperar el sentido irónico global en (7), el cual señala que calificar a la presunta reforma como "(h)educativa" resulta ser simplemente absurdo. Si uno se remite al texto del libro intitulado con ese enunciado o al (inter-)discurso asociado a la reforma educativa que se implementó en México entre los años 20122013, es posible hallar polémicas posiciones al respecto. ${ }^{16}$ En este caso, se trata de una postura crítica frente a dicha reforma constitucional, la cual no solo es rebatida mediante distintos argumentos en el libro (cfr. Martínez Gómez, 2015), sino tildada en el propio título de la obra.

$\{\mathrm{L}$ dice $X$ (= heducativa) $S E X$ es absurdo para $\lambda\}$

५POR LO TANTO la enunciación descalifica el decir de L2

Nuevamente, el blanco de burla remite (se focaliza) a una tercera persona plural (ellos): funcionarios de gobierno que impulsaron y aprobaron la reforma. Pero, a diferencia del caso anterior, el foco de dizque en (7) no está en el decir de L2, sino en el contenido X que se atribuye veladamente a al gobierno y sus funcionarios: calificar como "(h)educativa" a una reforma que es, según político-laboral.

Veamos, ahora, qué ocurre en el siguiente caso:

\footnotetext{
${ }^{14}$ Podría debatirse si este hecho discursivo pertenece a la doxa (AE: Marte PLT no vida) o remite a un locutor científico (L-Ciencia: no hay pruebas de vida en Marte PLT no hay Marcianos), pero eso no es materia para el presente análisis.

15 Del Río G arcía, E. (2015). La reforma dizque heducativa. México: Grijalbo.

${ }^{16}$ En su momento, se decía que se trataba de una reforma, más bien, politico-laboral, sin ningún sustento educativo: "dicha reforma, impulsada en México por la actual administración 'se hizo desde un escritorio sin pedir la opinión de los maestros' (p. 12) y tuvo, como finalidad, 'imponer una disciplina laboral entre el magisterio para controlarlo políticamente' (p. 13)" (Del Río, 2015 en Martínez Gómez, 2015: 231).
} 
(7) [...] Hacer competidores triunfadores es meta de todos los dirigentes deportivos de cualquier nación. Conseguir mayor número de medallas es motivo de orgullo para gobernantes y gobernados. Esto es comprensible y sin una práctica y organización adecuadas no se pueden lograr los éxitos que se buscan cuando se asiste a una competencia, sobre todo si ésta será vista por millones de personas. // Pero nada justifica que se sacrifique la salud y la vida de los competidores en aras de una dizque gloria nacional. Ninguna medalla es bienvenida si es producto del sacrificio inhumano que puede acabar con la existencia de quienes compiten por ellas [...]

En (8), el contenido X (= gloria) activa un discurso doxal asociado a la argumentación externa-estructural a la izquierda: sacrificio PLT gloria. Una paráfrasis de este discurso comúnmente aceptado bien puede ser: el sacrificio lleva a la gloria, o incluso, sin sacrificio no hay gloria (que corresponde al encadenamiento recíproco: neg. Y PLT neg. X). No obstante, si consideramos el texto completo (como fue en el caso de (5) que también apelaba a un discurso doxal), y aplicamos el significado irónico de dizque (dice(n) que $X$ $S E X$ es absurdo), lo que nos queda, ahora, es la exhibición de un interlocutor (L-dirigentes deportivos) a quien se le atribuye encubiertamente el contenido X': gloria PLT sacrificio \#inhumano. En efecto, (8) termina siendo una enunciación irónica, en tanto que L? se muestra como si sostuviera un discurso abiertamente absurdo (gloria PLT sacrificio de la salud y de la vida), al tiempo de manifestar un posicionamiento subjetivo de respuesta que exhibe la crueldad de su blanco de crítica:

$\left\{\right.$ Dicen $X^{\prime}$ (= gloria) $S E X$ es absurdo para $\left.\lambda\right\}$.

५POR LO TANTO la enunciación exhibe a L-dirigentes por sostener X'

Hasta aquí, hemos podido apreciar cómo es que el significado irónico de dizque toma por objeto discursos ajenos, en donde L? es plasmado como si estuviera homologado al decir o al/los contenido(s) semántico(s) que vehiculizan. Pero que, en el fondo, se muestran de alguna forma insostenibles o absurdos a través de indicios que puede hallarse o bien en el enunciado o bien en el cotexto o bien en el intertexto. Si tal inconsistencia es recuperada por el interlocutor, surge inmediatamente un efecto irónico [- ataque] o satírico [+ ataque] de descalificación y crítica a los interlocutores segundos o terceros evocados en el discurso ajeno. Pero ¿qué ocurre cuando las palabras absurdas son atribuidas a la primera persona?

\subsubsection{AUTOIRONÍA}

Recordemos que, de acuerdo con el propio Ducrot (1986), la autorionía surge cuando el locutor del enunciado se burla de las palabras de $\lambda$. Veamos, entonces, el siguiente ejemplo inventado, aunque absolutamente loable en el español de México:

(8) L2: ¿¿Hola, qué haces? 


\section{L1: -Aquí en la casa, dizque leyendo un cuento. ${ }^{17}$}

(Ejemplo inventado, llamada telefónica)

A continuación, buscaremos mostrar que en los casos como (9) dizque afecta la predicación completa (el decir), ya que funciona como un operador argumentativo de internalización transgresiva (Ducrot en Carel y Ducrot: 2005: 163-185). Una palabra $Y$ (dizque) funge como operador cuando es aplicada a una palabra $X(=$ leer $)$ y produce un sintagma $X Y(=$ dizque leer $)$ cuyo sentido está constituido por los encadenamientos argumentativos que contienen las palabras plenas presentes en X (ibíd.. 166-167). Los internalizadores (normativos/transgresivos) son un subtipo de operador en donde la AE de X se coloca al interior de la AI de XY (ibíd.: 169):18

\section{AE (norm.) leer: (leer PLT concentrarse) $\rightarrow$ (leer SE no concentrarse).}

El significado irónico de dizque activa, precisamente, el encadenamiento que pone en duda el aspecto léxico "normal" asociado al contenido X (concentrarse al leer) e internaliza la consecución "anormal" o transgresiva (distraerse al leer). De tal forma, es posible postular la AI de XY a partir del encadenamiento transgresivo de la AI de XY:

\section{AI-XY: dizque leyendo: leer SE no concentrarse}

De modo que, siguiendo nuestro análisis, el significado irónico de dizque se origina en un MD que habilita discursos absurdos atribuidos a $\lambda$ e introduce una respuesta dialógica de burla desenfadada de L sobre sí mismo19:

$\{$ Dije que X SE X es absurdo para $\lambda\}$

५POR LO TANTO la enunciación muestra a L burlándose de su propio decir.

(9) L2: - ¿Hola, qué haces?

L1: -Aquí en la casa, haciendo un dizque banquete para la cena

(Ejemplo inventado, conversación telefónica)

Por su parte, en (10) el significado irónico de dizque ya no afecta la predicación completa (el decir de $\lambda$ ), sino uno de los términos que vehiculiza el enunciado. De modo que, al igual que en los casos anteriores (2), (4) y (7),

\footnotetext{
${ }_{17}$ Nótese que leer un cuento es un sintagma verbales imperfectivos cuyo aspecto léxico (Aktionsart) es el de "actividad" (Vendler, 1957): eventos dinámicos sin punto final inherente.

${ }^{18}$ En el mismo texto (Carel y Ducrot, 2005) se señala que "la utilización de un internalizador permite elegir entre el un aspecto $(A C O N B)$ y su converso $\left(A C O N^{\prime}\right.$ neg. $\left.B\right)$ al construir el sintagma $X Y^{\prime}$ ' (ibíd.: 169). Asimismo, se plantea la dicotomía entre internalizadores transgresivos y normativos, la cual depende del tipo de conector que se recupera de la $\mathrm{AE}$ de la expresión afectada.

${ }^{19}$ Como señala Ducrot (1986), en la autoironía el L lleva a cabo "un acto de burla, y lo hace presentando una previsión cumplida por un enunciador del que él se distancia en el interior de su propio discurso (aun cuando tenga que identificarse con él en el mundo)" (ibíd.: 217).
} 
es posible afirmar que el foco de dizque está en el contenido X (= banquete). Entonces, el MD que explica la causa de la enunciación solo remite al contenido y dizque no se comporta como internalizador:

\{Dije que X SE X es absurdo para $\lambda$ \}

५POR LO TANTO la enunciación se burla del contenido $\mathrm{X}$ dicho por $\lambda$

Es decir, el sentido irónico de (10) señala como absurdo el calificar de cierta manera al predicado nominal en donde, no se trata de un banquete, sino de una cena cualquiera.

\section{Conclusión}

Este trabajo nos dispusimos a caracterizar las distintas modalidades con que se manifiesta el marcador adverbial 'dizque', prestando especial atención en el español de México. Nuestra hipótesis por defender es que existe un contraste gradual entre los significados que vehiculiza dizque. Primero, caracterizamos el significado citativo-canónico, en donde la predicación vehiculiza un discurso referido en modalidad directa o indirecta. En segundo lugar, describimos un significado evidencial, que añade un distanciamiento precautivo o escéptico respecto del discurso que se reporta. Y, en tercer lugar, delineamos un significado irónico, que se subdivide entre los casos en donde el blanco es distinto de L y la enunciación descalifica veladamente a su interlocutor y donde el blanco es L mismo y la enunciación se muestra como una burla desenfadada.

$\stackrel{\text { citativo } \quad \text { evidencial irónico }}{\longleftrightarrow}$
(1)
(2) (3)
(4)
(5)
(6)
(7)
(8)
(9) (10)

Foco: L2 L2-"X" L3a rumor doxa L2 L3a-X L-doxa $\lambda$ A-X

[+ neutral] [+ precaución][+rectificación] [+ descalificación] [+ burla]

Figura 2: Gradación de los significados citativo, evidencial e irónico(s)

Aunado a todo ello, mostramos que para recuperar el sentido de ciertas enunciaciones con dizque (en particular, las evidenciales y las irónicas) es preciso identificar los marcos de discurso (MD) que constituyen la causa de su enunciación. Asimismo, es posible recuperar diversas clases de posicionamientos subjetivos del locutor sobre el decir que vehiculiza su enunciación

Ciertamente, los efectos de sentido que surgen de cada significado son muy distintos. En los casos de evidencialidad, las enunciaciones con dizque permiten "decir sin decir" (García Negroni, comunicación en congreso) al habilitar la reproducción del contenido X sin que L se haga cargo de la argumentación interna del discurso que reproduce (dice X PLT es posible X). Mientras que, como se intentó mostrar aquí, en su modalidad irónica dizque permite, por un lado, contradecir un discurso presuntamente ajeno, que en 
realidad busca exhibir y/o descalificar. Y, por otro lado, dizque permite desdecir las palabras dichas o el propio decir del propio locutor y mostrar con ello una burla desenfadad de él mismo. Resta añadir que en cada modalidad se configura un ethos muy distinto, en las enunciaciones evidenciales se configura un ethos sensato, precavido e incluso escéptico; mientras que en la enunciaciones irónicas se configura, más bien, el ethos de un "falso ingenuo" (Berredonner, 2002) que utiliza su enunciación simulada para construir una critica velada o un burla desenfadada.

\section{REFERENCIAS}

AIKHENVALD, A. (2003): Evidentiality in typological perspective, en A. Y. Aikhenvald \& R. M. W. Dixon (Eds.), pp. 33-62.

AIKHENVALD, A. (2004): Evidentiality. Oxford: Oxford University Press.

ALCÁZAR, A. (2014): "On the Grammaticalization of dizque", en A. Enrique-Arias, M. J. Gutiérrez, A. Landa y F. Ocampo (eds.), Perspectives in the Study of Spanish Language Variation, Santiago de Compostela: Universidade de Santiago de Compostela, pp. 17-40.

ANSCOMBRE, J. C. (1995): Théorie des topoi, Editions Kimé.

ANSCOMBRE, J. C. \& DUCROT, O. (1983): L'argumentation dans la langue. Lieja: Pierre Mardaga.

BAJTÍN, M. M. [1952-1953] (1979): El problema de los géneros discursivos, Estética de la creación verbal, México: Siglo XXI.

BERRENDONNER, A. (2002): "Portrait de l'énonciateur en faux naïf ". Revue de sémiolinguistique des textes et discours, (15) [2/10/2018: https://journals.openedition.o $\mathrm{rg} / \mathrm{semen} / 2400]$

BLAKEMORE，D. (1994): "Evidence and modality". The Encyclopedia of language and linguistics, Oxford: Pergamon, pp. 11831186

BRUZOS MORO, A. (2005): “Análisis de la enunciación irónica: del tropo a la polifonía", Pragmalingüistica, 13, pp. 25-49.

CAREL, M. \& DUCROT, O. (2005). La semántica argumentativa: una introducción a la teoría de los bloques semánticos. Buenos Aires: Ed. Colihue. Trad: María Marta García Negroni y Alfredo M. Lescano.

CAREL, M. \& DUCROT, O. (1999) "Le problème du paradoxe dans une sémantique argumentative ", Langue française, 123, pp. 6-26.

CHAFE, W. L. \& NICHOLS, J. (1986): Evidentiality: The Linguistic Coding of Epistemology. Norwood, NJ: Ablex.

CORNILLIE, B. (2007): Evidentiality and Epistemic Modality in Spanish (Semi-) Auxiliaries. A Cognitive-Functional Approach. Berlin: Mouton de Gruyter.

DE LA MORA, J. \& MALDONADO, R. (2015): "Dizque: Epistemics blurring evidentials in Mexican Spanish", Journal of Pragmatics, 85, pp. 168-180.

DICCIONARIO DEL ESPAÑOL DE MÉXICO (DEM). El Colegio de México, A.C., [22/09/2019: http://dem.colmex.mx ].

DUCROT, O. (1986): El decir y lo dicho (Polifonía de la comunicación), Barcelona: Paidós.

DUCROT, O. (2004): "Sentido y argumentación". Elvira Arnoux y María Marta García Negroni (comps.) Homenaje a Oswald Ducrot, Buenos Aires: Eudeba. 
DUCROT, O. (2010): "Ironie et négation ". Ironie et un peu plus. Atayan, V., \& Wienen, U. Bern (eds.), Switzerland: Peter Lang.

GARCÍA NEGRONI, M. M. (2009): "Negación y descalificación. A propósito de la negación metalingüística”, Ciências e Letras, 45, pp. 61-82.

GARCÍA NEGRONI, M. M. (2016): "Discurso político, contradestinación indirecta y puntos de vista evidenciales. La multidestinación en el discurso político revisitada", ALED, 16, 1, 37-59.

GARCÍA NEGRONI, M. M. (2019): "El enfoque dialógico de la argumentación y la polifonía y la expresión de la evidencialidad. Un estudio contrastivo del español y del francés", RILCE. Revista de Filología Hispánica. 35, pp. 21-49

GARCÍA NEGRONI, M. M. (comunicación en el Congreso de Evidencialidad en el IIF de la UNAM, agosto, 2018): “Argumentación y puntos de vista evidenciales: acerca del condicional citativo en el discurso periodístico y en el discurso científico".

GARCÍA NEGRONI, M. M. y M. LIBENSON (2015): "Para una descripción polifónica de la evidencialidad. Subjetividad y estructuras evidenciales con pronombres demostrativos neutros", en García Negroni, M. M. (ed.), Sujeto(s), alteridad y polifonía. Acerca de la subjetividad en el lenguaje $y$ en el discurso, Buenos Aires: Ampersand, pp. 1749.

GARCÍA NEGRONI, M. M. \& LIBENSON, M. (2016), "Argumentación, evidencialidad y marcadores del discurso. El caso de por lo visto", Tópicos del seminario, 35, pp. 51-75.

GARCÍA NEGRONI, M. M., LIBENSON, M. \& MONTERO, A. S.
(2013): "De la intención del sujeto hablante a la representación polifónica de la enunciación. Acerca de los límites de la noción de intención en la descripción del sentido", Revista de Investigación Lingüística, 16, 1, pp. 237-262.

GARCÍA FAJARDO, J. (2009) "El modal dizque: estructura dinámica de sus valores semánticos". Entre las lenguas indigenas, la sociolingüistica y el español. Estudios en homenaje a Yolanda Lastra, Comp. Martha Islas. Lincom: Múnich, pp. 302325.

KANY C. E. (1944): "Impersonal dizque and Its Variants in American Spanish", Hispanic Review, Vol. 12, 2,168-177

MAGAÑA, E. (2005): "El paso de 'dice que' a 'dizque', de la referencia a la evidencialidad", Contribuciones desde Coatepec, 8, pp. 59-70.

MARTÍNEZ LEVY, A. R. (2017) “JJoder a México'. Hacia una lectura polifónico-argumentativa en clave dialógica de continuaciones discursivas gestadas a partir de un comentario del presidente mexicano Enrique Peña Nieto", RALED, 17, 1, pp. 53-75

MARTÍNEZ GÓMEZ, G. I. (2015): "Recensión: La dizque reforma heducativa", Revista Internacional de Educación para la Justicia Social, 4(2), pp. 231-232

OLBERTZ, H. (2005) "Dizque en el español de México", en Alba Valencia (comp.), Actas del XIV Congreso Internacional de la Asociación de Lingüistica y Filología de América Latina, Universidad Autónoma de Nuevo León, Monterrey: Morfosintaxis y Dialectología.

OLBERTZ, H. (2007): "Dizque in Mexican Spanish: the subjectification of reportative meaning", $R i$ vista di Linguistica, 19, 1, pp. 


\section{1-172.}

PHILER, B. (2019) “¿Cómo traducir la evidencialidad? La expresión de la fuente de información en Algunas variantes del español de América y sus equivalentes en esloveno", Colindancias, 9, pp. 249-267.

TRAVIS, C. E. (2006): “Dizque: a Colombian evidentiality strategy", Linguistics, 44/6, pp. 12691297.
WILLETT, T. (1988): “A cross-linguistic survey of the grammaticalization of evidentiality", Studies in Language, 2, pp. 51-97.

ZORRAQUINO M. A. \& PORTOLÉS, J. (1999), "Los marcadores del discurso", en Bosque, I. y Demonte, V. (dirs.), Gramática descriptiva de la lengua española, Madrid: Espasa Calpe. 